\title{
Successful quadruplet surrogate pregnancy after turbulent medical disorders in first trimester
}

\author{
Tochukwu C. Okeke ${ }^{1 *}$, Aikay A. Ubaka ${ }^{2}$, Augustine Olibe ${ }^{1}$, Kenechukwu O. Okeke ${ }^{3}$, \\ Godwin U. Odoh ${ }^{1}$, Cyril C. Ezenyeaku ${ }^{4}$, Lawrence C. Ikeako ${ }^{4}$, \\ Emmanuel O. Izuka ${ }^{1}$, Chidinma I. Onwuka ${ }^{1}$
}

\begin{abstract}
${ }^{1}$ Department of Obstetrics and Gynecology, University of Nigeria teaching Hospital (UNTH), Enugu, Nigeria ${ }^{2}$ Department of Medicine, Cimac Clinics, Enugu, Nigeria

${ }^{3}$ Department of Medicine, College of Medicine, UNEC, Enugu Campus, Enugu, Nigeria

${ }^{4}$ Department of Obstetrics and Gynaecology, Chukwuemeka Odumegwu-Ojukwu University Teaching Hospital, Amaku, Awka, Nigeria
\end{abstract}

Received: 14 March 2017

Accepted: 07 April 2017

*Correspondence:

Dr. Tochukwu C. Okeke,

E-mail: tcokeke2014@yahoo.com

Copyright: () the author(s), publisher and licensee Medip Academy. This is an open-access article distributed under the terms of the Creative Commons Attribution Non-Commercial License, which permits unrestricted non-commercial use, distribution, and reproduction in any medium, provided the original work is properly cited.

\begin{abstract}
Quadruplet surrogate pregnancy is a rare pregnancy but, has become common due to assisted reproductive technology (ART). Its management is a big challenge to obstetricians and co-clinicians worldwide. This was a pregnancy managed at the University of Nigeria Teaching Hospital (UNTH), Enugu, Nigeria in a 33 year old hypertensive surrogate mother with turbulent first trimester medical disorders that called for termination of the pregnancy by other co-managing clinicians. However, the pregnancy became stable in late 2nd trimester with emergency caesarean section at 33 weeks following preterm premature rupture of membranes (PPROM). Its management was a big challenge that necessitated multidisciplinary approach with successful outcome of four healthy live babies (three males and one female) and the controversial practice of surrogacy.
\end{abstract}

Keywords: Assisted reproductive technology, Multidisciplinary management approach, Quadruplet pregnancy, Surrogacy

\section{INTRODUCTION}

Quadruplets are a set of four off-springs born at one birth. An individual that is part of such a set is called a quadruplet and often referred to as "quads". ${ }^{1}$ Quadruplet is a higher order multiples pregnancy. Quadruplet births are becoming increasingly common due to fertility treatments and older age of some women that attempt pregnancy later in life. ${ }^{2,3}$ There are higher levels of follicle stimulating hormone (FSH) in older age of some women that have their ovaries respond more slowly to FSH stimulation. ${ }^{3}$
In spite of the advances in obstetric antenatal surveillance and easier recourse to early delivery, the occurrence of quadruplet pregnancy is fraught with adverse outcomes., ${ }^{4}$ The stillbirth rates and neonatal mortality in multiple maternities have remained markedly elevated contrasting with the fall in the singleton rates. ${ }^{5}$

Surrogacy is an agreement where a woman agrees to carry a pregnancy for another person(s), who will become the newborn child's parent(s) after birth. A commercial gestational surrogacy was established in which the embryo is created using the intended father's sperm and intended mother's eggs. The resulting child or children is genetically related to both intending parents. This type of 
surrogacy is called host or full surrogacy. ${ }^{6}$ If the surrogate receives monetary compensation it is termed commercial surrogacy. ${ }^{7}$ Gestational surrogacy was first achieved in April 1986. ${ }^{8}$ Surrogacy is a controversial practice worldwide, with issues of difficult moral, social, ethical, psychological, religious, cultural, technological and legal problems. ${ }^{8,9}$ The legal situation varies considerably with many countries without laws backing surrogacy. ${ }^{8,9}$ There is no transparency in surrogacy contract and chances of legal problems are high. ${ }^{9}$ In addition, couple's emotional, ethical, moral and religious views complicate decisions about fertility treatment. However, parental autonomy, privacy and choices deserve utmost respect from caregivers. ${ }^{8-10}$

This case report attempts to report the quadruplet surrogacy, the obstetric morbidity presented to the mothers and infants in quadruplet births.

\section{CASE REPORT}

A 33-year old trader, a known hypertensive and epileptic, a commercial gestational surrogate was referred from Cimac Clinics to the Department of Obstetrics and Gynaecology of the UNTH on $20^{\text {th }}$ June 2016 with history of quadruplet pregnancy and severe first trimester medical disorder in pregnancy. She was G2 P1, A1. She had in vitro fertilization and embryo transfer (IVF-ET) on $9^{\text {th }}$ April 2016 for Mrs. AA who had 3 failed attempts at IVF-ET. Her first day of last menstrual period (LMP) was on $26^{\text {th }}$ March, 2016 and the expected date of delivery (EDD) was on $2^{\text {nd }}$ January 2017. She was admitted at a gestational age (GA) of 10 weeks +4days and was in the hospital till delivery due to severe turbulent medical disorders that necessitated multidisciplinary management approach. Other information is shown on the table of the case report below.

Table 1: Table of the case report.

\begin{tabular}{|c|c|}
\hline Socio-demographic characteristics. & Maternal and feto-neonatal outcome. \\
\hline Name & Miss M.N \\
\hline Age & 33 years \\
\hline Marital Status & Single \\
\hline Tribe & Ibo \\
\hline Religion & Christianity \\
\hline Occupation & Trading \\
\hline L.M.P & $26 / 3 / 2016$ \\
\hline E.D.D & $02 / 01 / 2017$ \\
\hline GA at booking & 10 weeks +4days \\
\hline Source of embryo & From the parents \\
\hline Number of embryo transferred & Four \\
\hline Date of embryo transfer & $9 / 4 / 2016$ \\
\hline Date of cervical circlage & $26 / 7 / 2016$ at 17 weeks \\
\hline Fetal monitoring & Serial ultrasound \\
\hline Type of Conception & IVF-ET through a commercial gestational surrogate \\
\hline Date of delivery & $11 / 11 / 2016$ at 33 weeks \\
\hline Mode of delivery & Emergency lower segment caesarean section \\
\hline Indication & PPROM with oligohydramnios in one gestational sac \\
\hline \multirow{4}{*}{ Findings at Surgery } & Enlarged abdomen/uterus \\
\hline & Clean peritoneal cavity \\
\hline & Well formed lower uterine segment \\
\hline & Normal ovaries and fallopian tubes \\
\hline Estimated blood loss & 1.2 litres \\
\hline Four Live Fetuses & F1 F2 F3 F4 \\
\hline Weights & $1.75 \mathrm{~kg} 1.9 \mathrm{~kg} 1.65 \mathrm{~kg} 1.65 \mathrm{~kg}$ \\
\hline Apgar scores & $8 / 106 / 106 / 108 / 10$ \\
\hline Presentation & Breech Breech Cephalic Transverse \\
\hline Placenta & One big placentae: 4 fused placental portions \\
\hline Haemostasis & $\begin{array}{l}\text { Adequate haemostasis achieved, } 600 \mathrm{mcg} \text { of misoprostol inserted } \\
\text { rectally post operatively to prevent postpartum haemorrhage (PPH) }\end{array}$ \\
\hline Babies & Transferred immediately to newborn special care unit (NBSCU) \\
\hline 48 hour postoperative haemoglobin & $9.8 \mathrm{~g} / \mathrm{dl}$ \\
\hline Management Approach & $\begin{array}{l}\text { Multidisciplinary (obstetrician, cardiologist, neurologist, respiratory } \\
\text { physician, ophthalmologist, anaesthetist, neonatologist, midwife and } \\
\text { patient herself) }\end{array}$ \\
\hline
\end{tabular}




\section{DISCUSSION}

Quadruplets can be fraternal (multizygotic), identical (monozygotic) or a combination of both. Our quadruplet is a combination of multizygotic and monozygotic of four healthy babies ( 3 males and one female) of in vitro fertilization embryo transfer (IVF-ET) in a commercial gestational surrogate. It is important to note that spontaneous conception and its sequence to quadruplets is rare but assisted reproductive technology (ART) has made multiple gestations increasingly common worldwide. ${ }^{2,4,9-11}$

In April 29, 2016, four embryos were transferred to the commercial gestational surrogate via IVF-ET program while oocytes and spermatozoas came from the actual parents of the quadruplets. The parents had 3 failed attempts at IVF-ET programs that necessitated for surrogacy.

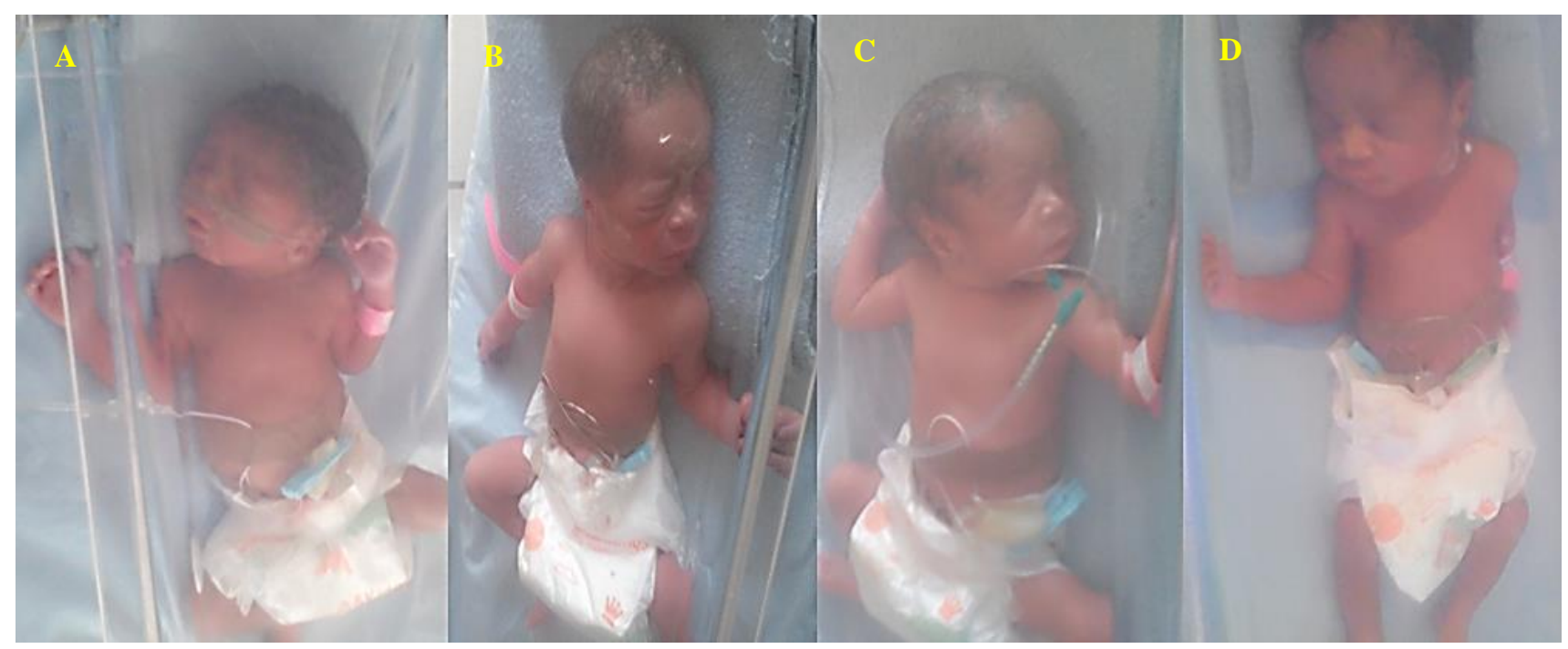

$\mathrm{A}=$ Male, Breech, 1.75kg, Membrane ruptured,Apgar scores: 8/10; B=Male, Breech, 1.9kg Membrane Intact, Apgar scores: 6/10; $\mathrm{C}=$ Male, Cephalic, $1.65 \mathrm{~kg}$ Membrane Intact, Apgar scores: 6/10; D=Female, Transverse lie, 1.65kg Membrane Intact, Apgar scores: $8 / 10$

Figure 1: The quadruplet.

The recommended number of embryos transferred during each cycle should not be more than two. ${ }^{2,12}$ The transfer of four embryos is based in the private sector and did not follow the guideline from the National Institute for Health and Care Excellence (NICE) or ensures elective single embryo transfer versus two-embryo transfer in first IVF/ICSI cycles. ${ }^{13,14}$ The appropriate number of embryos to be transferred depends on the age of the woman, whether it is the first, second or third full IVF cycle attempt and whether there are top-quality embryos available. It is also recommended to use single embryo transfer in all situations if a top-quality blastocyst is available. ${ }^{13}$

During pregnancy, the morbidity of the mothers is significantly increased due to the likelihood of the development of hypertensive disease, gestational or pregestational diabetes, incompetent cervix and antepartum haemorhage..$^{15}$ There is risk of pre-eclampsia, eclampsia, preterm labour, and premature rupture of membranes (PROM), anaemia, urinary tract infection, postpartum haemorrhage, puerperal endometritis and caesarean delivery. This pregnancy was turbulent with marked medical disorders in first trimester that resulted in hospitalization from 11 weeks till delivery. Due to the associated medical disorders, this pregnancy necessitated multidisciplinary approach involving the obstetricians, cardiologist, respiratory physician, ophthalmologist, neonatologist, anaesthetist, experienced midwife and the patient herself. The patient had PPROM at 33 weeks even with the cervical cerclage that was inserted at 17 weeks of gestation.

The average gestation for a quadruplet pregnancy is 30 weeks as opposed to 40 weeks for a full term baby. ${ }^{16}$ However, these babies were delivered at 33 weeks following premature rupture of membranes (PROM) with oligohydramnios in one gestational sac through emergency caesarean section.

Quadruplet infants are admitted to newborn special care unit (NBSCU) to undergo intensive treatment in the special care baby unit due to prematurity and low birth weight (LBW) in order to attain certain newborn weight adequate for discharge from NBSCU. ${ }^{5}$ The babies of our quadruplet (Figure 1) were admitted to NBSCU for 
prematurity and further management. The long-term morbidity of the surviving infants has not been measured. ${ }^{5}$ The main cause for the increasing morbidity and mortality arises from the medical problems of prematurity and low birth weight (LWB). Management of these babies is highly demanding and places a lot of handicaps to limited facilities in the only NBSCU in this hospital. This is compounded by psychological and emotional strains placed on the medical and paramedical staff of these units.

In spite of advances in obstetric care, the prenatal outcomes associated with a quadruplet pregnancy remains associated with increased morbidity and mortality for the mother and the infants. ${ }^{15}$ There is enormous financial, emotional and psychological trauma experienced by the couples during their intensive treatment for their infertility and when faced with the mortality or morbidity of their child as a result of interventions they had undergone. ${ }^{5}$

The effects of quadruplets on family life are substantial. The impact of multiple births affects the parents, babies, other siblings and the extended family. Financial burdens are common due to the additional costs of feeding, clothing, housing and caring for multiple children. Postpartum depression is also more common after delivery of multiple pregnancies in both mother and father and in long-term basis. ${ }^{5}$ There may be need for psychological counseling and support groups in order to provide a lifeline for the parents of quadruplets who may feel isolated or depressed. ${ }^{5,17}$

Surrogacy is fraught with issues of moral, legal, social, ethical and technological problems. ${ }^{9}$ Both contract and the finalization of parental rights can be complicated. The surrogacy contract should be drafted, reviewed and signed at the beginning of the relationship between the intended parents and the surrogate. A solid contract will outline the rights and the responsibilities of the intended and the surrogate as well as compensation, medical and psychological screening, selective reduction policy, medical insurance and parental rights. ${ }^{9}$ In addition to drafting the contract, the intending parents must finalize their parental rights in order to be recognized as legal parents.

\section{CONCLUSION}

Quadruplet is a high risk, a higher order multiples gestation. A challenge to obstetricians, that requires special attention and care in a tertiary hospital with wellequipped NBSCU. Its management involves multidisciplinary approach and delivery by caesarean section by an experienced obstetrician who will observe strict vigilance in order to prevent postpartum haemorrhage (PPH).

Surrogacy is a controversial practice but it is of assistance to couples with infertility. Some multiple pregnancies and their complications are an inevitable risk for fertility therapies, education about the risks is crucial prior to treatment. However, prevention is the key to reducing the risk of multiples pregnancy.

\section{Funding: No funding sources \\ Conflict of interest: None declared \\ Ethical approval: Not required}

\section{REFERENCES}

1. Oxford English Dictionary, 2nd edition: quads used for quadruplets.

2. Elsner CW, Tucker MJ, Sweitzer CL, Brockman WD, Morton PC, Wright G et al. Multiple pregnancy rate and embryo number transferred during in vitro fertilization. Am J Obstet Gynecol. 1997;177(2):3505 .

3. Beemsterboer SN, Homburg R, Gorter NA, Schats R, Hompes PG, Lambalk CB. The paradox of declining fertility but increasing twinning rates with advancing maternal age. Human Reprod. 2006;21(6):1531-2.

4. Begum H, Moniruddin ABM, Jahan S. Quadruplet pregnancy: A rare occurrence. The Orion Med J. 2008;30: 570-1.

5. Savona-Ventura C, Gatt M, Vella K, Grima S. Higher order multiple pregnancy outcomes in the Maltese Islands. 2000-2004. Malta Med J. 2008;20(1):19-23.

6. Imrie S, Jadva V. The long-term experiences of surrogates: relationships and contact with surrogacy families in genetic and gestational surrogacy arrangements. Reprod Bio Medi Online. 2014;29(4):424-35.

7. Reproductive Law. Lisa Feldstrin Law Office. Retrieved October 6, 2016.

8. Umeora OJ, Umeora MC, Emma-Echiegu NB, Chukwuneke FN. Surrogacy in Nigeria: Legal, ethical, socio-cultural, psychological and religious musings. Afr J Med Health Sci. 2014;13(2):105-9.

9. Anu, Kumar P, Inder D, Sharma N. Surrogacy and women's right to health in India: Issues and perspective. Indian J Public Health. 2013;57(2):6570.

10. Pector EA. Ethical issues of high-order multiple births. Newborn and Infant Nursing Reviews. 2005;5(2):69-76.

11. Savona-Ventura C, Vella A, Zammit K. Temporal trends in multiple pregnancy rates in the Maltese Islands. Int J. Risk Safety Med. 2006;18(3):173-9.

12. Wang J, Lane M, Norman RJ. Reducing multiples pregnancy from assisted reproduction treatment: educating patients and medical staff. Med Journal of Australia. 2006;184(4):180-1.

13. Fertility: assessment and treatment for people with fertility problems. NICE Clinical guideline CG 156Issued: February 2013.

14. Gerris J, De Sutter P, De Neubourg D, Van Royen E, Vander Elst J, Mangelschots $\mathrm{K}$ et al. A real-life prospective health economic study of elective single 
embryo transfer versus two-embyro transfer in first IVF/ICSI cycles. Human Reprod. 2004;19(4):91723.

15. Conde-Agudelo A, Belzian JM, Lindmark G. Maternal morbidity and mortality associated with multiple gestations. Obstet Gynaecol. 2000;95:899904.

16. Martin JA, Hamilton BE, Sutton PD, Osterman MJK, Curtin SC, Mathews TJ. Births: final data for 2002.
Centres for disease control and prevention. Natl Vital Stat Rep. 2002;52:1-114.

17. Australian Multiple Birth Association (AMBA). Available from: http://www.amba.or.au/(Australia).

Cite this article as: Okeke TC, Ubaka AA, Olibe A, Okeke KO, Odoh GU, Ezenyeaku CC et al.

Successful quadruplet surrogate pregnancy after turbulent medical disorders in first trimester. Int $\mathbf{J}$ Reprod Contracept Obstet Gynecol 2017;6: 2090-4. 